\title{
There is no Relationship with Plasma Fatty Acid Levels in New Zealanders with Severe Coronary Artery and Mortality
}

Jocelyne R Benatar*

Green Lane Cardiovascular Service, Auckland City Hospital, Auckland, New Zealand

\begin{abstract}
Background: Objective measures of fatty acid intakes such as tissue levels of fatty acids more accurately reflect dietary intake compared to food frequency questionnaires. This study describes plasma fatty acid levels in New Zealanders with significant coronary artery disease and the relationship with mortality at 7.5 years.

Methods: This is prospective observational study. Fasting plasma samples were taken in in 420 consecutive patients with angiographic diagnosis of severe coronary disease requiring coronary artery bypass surgery. Plasma levels of fatty acids were measured by gas-chromatography mass-spectrometry. Mortality data was obtained by accessing details of the most recent contact with health professionals, review of clinical notes and the National Health Index database and death certificates.

Results: The mean age of participants was $68( \pm 10)$ years and $83 \%$ were male. Saturated fats were $46.5( \pm$ $1.2) \%$, unsaturated fats were $51.8( \pm 1.3 \%) \%$, trans fatty acids $1.1( \pm 0.69) \%$ of total fats. Ruminant transfatty acids made up $67 \%$ of total plasma trans fatty acids. Saturated fats and ruminant trans fatty acids levels were not associated with increased total mortality (hazard ratio $0.93(0.75$ to 1.16$) p=0.53$ and $.14(0.85$ to 1.53$) p=0.39$ respectively or cardiovascular mortality (hazard ratios $0.93(0.75$ to 1.16$) p=0.53$ and $0.91(0.61$ to $1.37, p=0.66)$.

Conclusion: Saturated and trans fatty acid levels in this population are higher than expected from food frequency questionnaires. More than two thirds of transfatty acids are from dairy food and meat. Neither saturated fats nor transfatty acids are associated with increased cardiovascular and total mortality.
\end{abstract}

Keywords: Trans; Saturated; Fats; Dairy; Mortality; Cardiovascular

\section{Introduction}

Evidence suggests that there may be a relationship between certain fatty acids and cardiovascular disease. For example, observational studies suggest that Trans Fatty Acids (TFA) is associated with increased total and cardiovascular mortality $[1,2]$. However, most TFA in those populations is derived from partially hydrogenated vegetable oil, with little coming from ruminant sources [3-13]. The effects of TFA derived from animal byproducts is less clear with one author suggesting that all TFA regardless of source is associated with increased mortality but others suggesting that ruminant TFA(rTFA) have no effect $[2,14]$.

A Cochrane review contends a small, but potentially important, reduction in cardiovascular risk with reduced SFA intake [15]. The postulated effects of SFA on heart heath are thought to depend on the type of SFA. For example, long chain fatty acids are thought to be harmful but medium chain fatty acids are thought to have neutral or beneficial effects. However, the recent meta-analysis by Rajiv Chowdhury and review by Siri-Tano suggests that there is little distinction between the effects of different SFA isomers [16-18].

Meal diaries and food frequency questionnaires have been found to be unreliable to assess dietary intake $[19,20]$ and it is now suggested that objective measurements of dietary intake be more widely used. One such measurement is plasma levels fatty acids which reflect dietary intake for the last 2-3 weeks [21]. In this study, plasma level of all fatty acids including TFA isomers was measured in New Zealand subjects with severe symptomatic coronary artery disease. The relationship between total and cardiovascular mortality at7 $1 / 2$ years and fatty acid levels was described.

\section{Methods}

This is a prospective observational study .The primary study endpoint of this study is all-cause and cardiovascular mortality at $71 / 2$ years.

\section{Study population and clinical data}

Four hundred and twenty two sequential patients with symptomatic severe coronary artery disease diagnosed by angiography were invited to participate in this observational study from August 2004 to September 2006. Ethics approval was obtained. All participants provided written informed consent after the diagnostic coronary angiogram.

\section{Measurement of FA and biomarkers}

Fasting blood samples were taken in ethylene-diamine-tetra acetic acid tubes. Plasma was separated and stored at $-70^{\circ} \mathrm{Celcius}$ until analysis. Plasma Phospholipids analysis was performed at the Nutrition and Functional Food Science Laboratory, the University of Adelaide, Australia. Total lipids were extracted with AR Methanol and fatty acid methyl esters formed by transmethylation [22]. Serum phospholipid fatty acid composition was assessed by gas chromatography (Hewlett Packard 6890 Gas Chromatograph with an SGE BPX70 column and a Flame Ionisation Detector). 18:1n-7t (vaccenic acid), 18:1n-9t (elaidic acid), 18:2t (linoelaidic acid), 16:1t and total TFA were measured.

*Corresponding author: Jocelyne Benatar, Cardiovascular Research Unit, Greenlane Cardiovascular Service, Auckland City Hospital, Auckland 1030, New Zealand, Tel: +64-9-307 4949; Fax: +64-9-630 9978; E-mail: JBenatar@adhb.govt.nz

Received June 28, 2014; Accepted September 18, 2014; Published September 26, 2014

Citation: Benatar JR (2014) There is no Relationship with Plasma Fatty Acid Levels in New Zealanders with Severe Coronary Artery and Mortality. J Nutr Disorders Ther 4: 146. doi:10.4172/2161- 0509.1000146

Copyright: (c) 2014 Benatar JR. This is an open-access article distributed under the terms of the Creative Commons Attribution License, which permits unrestricted use, distribution, and reproduction in any medium, provided the original author and source are credited. 
Citation: Benatar JR (2014) There is no Relationship with Plasma Fatty Acid Levels in New Zealanders with Severe Coronary Artery and Mortality. J Nutr Disorders Ther 4: 146. doi:10.4172/2161- 0509.1000146

Page 2 of 4

Levels are expressed as the percentage of the $\mathrm{g} / 100 \mathrm{~g}$ of the plasma phospholipids acids.

CRP was measured using a high sensitivity assay using the Roche CRPLX immunoturbidimetric method on a Roche Modular analyzer and levels are expressed as (mg/dl). BNP was measured using the Advia Centaur BNP assay (Bayer Diagnostics and levels are expressed as $\mathrm{pmol} / \mathrm{L}$. Creatinine was measured using Roche Modular P unit (Roche Diagnostics). Levels are expressed as $\mathrm{mmol} / \mathrm{l}$.

\section{Attainment of mortality status}

This was obtained initially by reviewing the National Health index database. Patients were deemed alive as of 01February 2014 if no date of death was listed in the National Health Database and evidence of patient contact was found. Contact was defined as evidence of a face to face visit to the general practitioner, hospital, and laboratory or community pharmacy in the month of February 2014. Contact was determined by checking hospital notes, laboratory results and contacting the general practitioner.

For those who had died, hospital notes, laboratory and radiology tests and death certificates were reviewed, and when not available, information was obtained from the general practitioner.

\section{Clinical definitions}

Cardiovascular death was defined as death resulting from an acute myocardial infarction, sudden cardiac death, death due to heart failure, death due to stroke, and death due to other cardiovascular causes [23].

\section{Statistical analysis}

Two hundred and fourteen participants was estimated to give $90 \%$ power to detect a difference in fatty acid levels between the two groups (alive and dead), with a two-sided 0.05 significance level, if the true difference in fatty acids between groups is $0.02 \%$ with a SD of 0.1 .

Results are presented as mean and standard deviation for population characteristics and median and Interquartile Range (IQR) for FA levels and biomarkers.

The Mann Whitney U test was conducted to determine differences in SFA and TFA levels between those who died and were still alive and to compare age, C- reactive protein, creatinine, white cell count and BNP between the two groups.

The distribution of ethnicity and gender between the groups was compared with the two-sample $\mathrm{Z}$ test. Univariate Cox proportional hazard regression was used to assess the relationships between SFA and TFA with total mortality, CV mortality and non CV mortality. Statistical analyses were performed using the statistical package SAS version 9.3 (SAS Institute, Cary, NC). All p-values resulted from two sided tests and a p-value of $<0.05$ was considered statistically significant.

\section{Results}

Baseline characteristics for the 422 patients included in the study are presented in (Table 1$)$. The mean age was $68( \pm 10)$ years and $83 \%$ were male. The majority of participants were of European descent (55\%), with a smaller proportion Maori (14\%), Pacific Islander (6\%), South Asian 27 (7\%) or other ethnicity 92 (23\%). Cardiovascular risk factors included a history of present or past smoking (73\%), hypertension (53\%) and diabetes treated with pharmacotherapy (27\%). The average body mass index was 28 (SD 4.7 ) $\mathrm{kg} / \mathrm{m}^{2}$ and waist circumference 101 $( \pm 12.5) \mathrm{cm}$.Saturated fats were 46.6 (IQR 45.8 to 47.3 ) \%, unsaturated

\begin{tabular}{|l|l|}
\hline No. of Subjects & $\mathbf{4 2 2}$ \\
\hline Age & $68( \pm 10)$ \\
\hline Male & $350(83 \%)$ \\
\hline Smoker & $312(74 \%)$ \\
\hline Body mass index $\left(\mathrm{kg} / \mathrm{m}^{2}\right)$ & $28.0( \pm 4.7)$ \\
\hline Waist circumference $(\mathrm{cm})$ & $100.5( \pm 12.5)$ \\
\hline Diabetes & $114(27 \%)$ \\
\hline Hypertension & $287(53 \%)$ \\
\hline Statin & $248(59 \%)$ \\
\hline Beta blocker & $241(57 \%)$ \\
\hline LDL cholesterol $(\mathrm{mmol} / \mathrm{l})$ & $2.5( \pm 1.0)$ \\
\hline HDL cholesterol $(\mathrm{mmol} / \mathrm{l})$ & $1.3( \pm 0.4)$ \\
\hline
\end{tabular}

Table 1: Baseline characteristics of study population.

Results are number (percent) or mean (standard deviation) as appropriate.

fats were 51.8 (IQR 50.5 to 53.0 ) \%, TFA 0.84 (IQR 0.67 to 1.20 ) \% in the total cohort. The median plasma levels of the four trans fatty acids measured were as follows: palmitelaidic acid 0.081 (IQR 0.04 to 0.22 ) $\%$, vaccenic acid 0.45 (IQR 0.35 to 0.72 ) \%, elaidic acid 0.19 (IQR 0.13 to 0.25 ) \% and linoelaidic acid 0.09 (IQR 0.07 to 0.11 ) \%.

Average follow up was for $7.5( \pm 0.8)$ years and mortality status and cause of death were available for 421 of the 422 of the cohort. One participant had left New Zealand and no follow-up information was retrievable. All but 13 of the original cohort had coronary artery bypass surgery and in total 95 (22.5\%) were dead as of $1^{\text {st }}$ February 2014.

Gender and race did not predict mortality; however, the inverse was true for increased age, creatinine, inflammatory markers (C reactive protein) and Brain- Natriuretic Peptide (BNP) (Table 2). When multivariate analysis was performed, $\mathrm{C}$ - reactive protein was no longer significant $(\mathrm{p}=0.06)$, but age, creatinine and BNP remained significant with $\mathrm{p}<0.001$ for all three.

Table 3 shows association of SFA and TFA with total mortality. Total SFA did not predict total mortality (hazard ratio 0.98 (0.64 to 1.44), $\mathrm{p}=0.64$, or cardiovascular mortality (hazard ratio 0.93 (0.75 to 1.16) $\mathrm{p}=0.53$ ). No saturated fat isomer was associated with increased mortality. Similarly, total TFA did not predict total mortality (hazard ratio1.14 (0.85 to 1.53$) \mathrm{p}=0.39)$ or cardiovascular mortality (hazard ratio 0.91 ( 0.61 to $1.37, \mathrm{p}=0.66$ ). Whilst linoelaidic acid was associated with increased total mortality $(\mathrm{p}=0.023)$, levels were very low with markedly skewed distribution to the left.

\section{Discussion}

SFA and TFA levels in this population are higher that than expected from food frequency questionnaires [24]. The most common fats in this population with significant cardiovascular disease are the long chain fats, palmitic and stearic acid. Ruminant TFA made up $67 \%$ of the total TFA in this population whereas in most developed countries industrial TFA is more common [3,5]. The relatively high levels of SFA and rTFA may reflect the high intake of dairy food in the New Zealand population. Dairy food is the most significant source of animal fat in the human diet and New Zealanders have a relatively high intake of this [24]. As one of the world's most significant producers of dairy food this has been strongly promoted as part of healthy diet. The relatively high TFA levels may also be partly explained by the practice of grass feeding cows in New Zealand that increases TFA content in milk $[25,26]$.

TFA is consistently associated with increased mortality in cohorts with higher TFA levels that are mainly derived from partially hydrogenated vegetable fat $[2,3,17]$. However, TFA levels in this 


\begin{tabular}{|l|l|l|l|l|}
\hline & Alive (n=327) & Dead (n=95) & $\begin{array}{l}\text { P } \\
\text { (unadjusted) }\end{array}$ & $\begin{array}{l}\text { P } \\
\text { (adjusted) }\end{array}$ \\
\hline Female & $52(78 \%)$ & $20(22 \%)$ & 0.43 & 0.59 \\
\hline Male & $273(79 \%)$ & $75(21 \%)$ & 0.43 & 0.59 \\
\hline Age (years) & $\begin{array}{l}73.9(65.1 \text { to } \\
78.6)\end{array}$ & $67.3(59.6$ to 74.6$)$ & $<0.0001$ & $<0.0001$ \\
\hline $\begin{array}{l}\text { CRP } \\
\text { (mg/dl) }\end{array}$ & $3.8(1.4$ to 13.7$)$ & $2.4(1.1$ to 6.2$)$ & 0.005 & 0.05 \\
\hline $\begin{array}{l}\text { Creatinine } \\
\text { (mmol/l) }\end{array}$ & $121(100$ to 150$)$ & $107(92$ to 125$)$ & $<0.0001$ & $<0.0001$ \\
\hline WBC (E+9/l & $11.7(8.9$ to 15.9$)$ & $12.6(10.3$ to 15.2$)$ & 0.18 & 0.48 \\
\hline $\begin{array}{l}\text { BNP } \\
\text { (pmol/L) }\end{array}$ & $112(40$ to 309$)$ & $33(15$ to 88$)$ & $<0.0001$ & $<0.0001$ \\
\hline
\end{tabular}

Table 2: Baseline characteristic of those who were alive or dead at 7.5 years of follow up. Results are median (IQR) or number (\%) as appropriate. When multivariate analysis was performed for all risk factors that that had unadjusted $p<0.05$, BNP remained significant $(p<0.001)$, but CRP was no longer significant $(p=0.052)$.

\begin{tabular}{|c|c|c|c|}
\hline $\begin{array}{l}\text { Fatty acid (\% total fatty } \\
\text { acids) }\end{array}$ & Median (IQR) & Median (IQR) & $P$ value \\
\hline Myristic acid C14:0 & 0.21 (0.18 to 0.26$)$ & 0.21 (0.17 to 0.26$)$ & 0.20 \\
\hline $\begin{array}{l}\text { Pentadecanoic acid } \\
\text { C15:0 }\end{array}$ & 0.19 (0.16 to 0.22$)$ & 0.20 (0.18 to 0.23$)$ & 0.37 \\
\hline Palmitic acid C16:0 & $0.70(0.62$ to 0.80$)$ & $0.72(0.63$ to 0.80$)$ & 0.25 \\
\hline Margaric acid $\mathrm{C} 17: 0$ & $0.48(0.42$ to 0.53$)$ & $0.50(0.43$ to 0.54$)$ & 0.48 \\
\hline Stearic acid C18:0 & 0.51 (0.33 to 0.66$)$ & $0.46(0.00$ to 0.67$)$ & 0.48 \\
\hline Arachidic acid C20:0 & $0.50(0.43$ to 0.58$)$ & 0.51 (0.43 to 0.59$)$ & 1.00 \\
\hline Behenic acid 22:0 & $0.49(0.41$ to 0.56$)$ & 0.47 (0.40 to 0.56$)$ & 0.10 \\
\hline Lignoceric acid C24:0 & 0.59 (0.52 to 0.67$)$ & 0.57 (0.49 to 0.66$)$ & 0.08 \\
\hline Total saturated fats & 46.52 (45.81 to 47.23$)$ & 46.52(45.66to 47.29) & 0.97 \\
\hline $\begin{array}{l}\text { Palmitelaidic acid } \\
\text { C16:1 (n-7t) }\end{array}$ & 0.08 (0.04 to 0.23$)$ & 0.09 (0.05 to 0.17$)$ & 0.62 \\
\hline Elidic acid C18:1 (n-9t) & $0.19(0.13$ to 0.25$)$ & $0.19(0.12$ to 0.27$)$ & 0.45 \\
\hline $\begin{array}{l}\text { Vaccenic acid C18:1 } \\
(\mathrm{n}-7 \mathrm{t})\end{array}$ & 0.44 (0.35 to 0.77$)$ & 0.46 (0.37 to 0.67$)$ & 0.46 \\
\hline $\begin{array}{l}\text { Linoelaidic acid } \\
\text { C18:2 (n-6t,9t) }\end{array}$ & $0.09(0.07$ to 0.10$)$ & $0.10(0.08$ to 0.11$)$ & 0.03 \\
\hline Total trans fatty acids & $0.84(0.66$ to 1.29$)$ & $0.89(0.71$ to 1.20$)$ & 0.39 \\
\hline
\end{tabular}

Table 3: Saturated and trans fatty acid levels in those who were alive or dead at 7.5 years of follow up. Results are expressed as \% total fatty acids and are reported as median and interquartile range.

study were relatively low and were mainly rTFA, consistent with food frequency questionnaires[24]. Little is known about effects of rTFA on mortality. One author suggests that all TFA regardless of source is associated with increased mortality but others suggest that rTFA have no effect $[2,14]$. Some observational studies show an association with increased cardiovascular disease in a dose dependent manner and others show little effect $[11,12,14,27]$. An experimental study suggests that rTFA, has little effect on lipids and inflammatory markers at low doses but has adverse effects on cholesterol homeostasis at higher doses $[1,28,29]$. In this study, total TFA and rTFA did not predict total or cardiovascular mortality. Whilst there is a suggestion that linoelaidic acid was associated with increased mortality, the results need to be interpreted with extreme caution as levels were very low and there was a markedly skewed distribution to the left.

Most of the SFA in this population were the long chain fatty acids and these were not associated with increased mortality. Levels of short chain and medium chain fatty acids were too low to reliably draw conclusions. This study contrast with others that suggest that long chain fatty acids and total SFA are associated with increased cardiovascular mortality [30,31]. But is consistent with the most recent meta- analysis by Rajiv Chowdhury and review by Siri-Tano suggests [17]. Emerging evidence also suggests that a low fat diet may not be effective at reducing cardiovascular disease, compared to a diet where SFA is substituted with PUFAs $[32,33]$. In countries that have embraced a low fat diet, there are increased rates of diabetes and obesity, thought to be due to a compensatory increase in the consumption of carbohydrates [34,35].

In this study, creatinine, age and BNP measured at time of diagnosis are associated with increased risk of death after coronary artery bypass surgery. These finding concur with other studies that have found that these risk factors are associated with increased mortality in patients with cardiovascular disease [24-26]. However, the findings that preoperative BNP predict mortality e after patients have had complete revascularization despite adjustments for the most significant risk factors for post-operative mortality is novel and will need further study $[36,37]$.

The strength of this study is that survival information on all but 1 participant was available, and the cause of death was able to be ascertained on all participants.

The limitations of this study are that information on diet was not collected and only one blood test was collected. Relation between plasma levels of different FA and diet could therefore not be directly assessed. The single blood test excludes evaluation of variation of levels over time. Dietary studies suggest that the majority of the population have a consistent eating pattern, so it is expected that there is a small variation of fatty acid levels within individuals [38]. The study has been undertaken in patients with severe coronary artery disease; it is possible that the fatty acid levels seen in this study do not reflect levels in the general population.

\section{Conclusion}

This study suggests that in New Zealand patients with significant coronary artery disease, total plasma TFA levels are low, and these are mainly derived from meat and dairy. SFA and TFA levels are higher than expected from dietary modeling. These fatty acids are not associated with increased risk of total and cardiovascular mortality.

\section{Acknowledgement}

We thank all the patients who participated in the study, the research staff of Green Lane Cardiovascular Research Unit, Auckland City Hospital, the Fatty Acid Lab and The University of Adelaide who assisted in the measuring of fatty acid levels.

\section{References}

1. Mozaffarian D, Aro A, Willett WC (2009) Health effects of trans-fatty acids: experimental and observational evidence. Eur J Clin Nutr 63 Suppl 2: S5-21.

2. Bendsen NT, Christensen R, Bartels EM, Astrup A (2011) Consumption of industrial and ruminant trans fatty acids and risk of coronary heart disease: a systematic review and meta-analysis of cohort studies. Eur J Clin Nutr 65 773-783.

3. Lemaitre RN, King IB, Mozaffarian D, Sotoodehnia N, Rea TD, et al. (2006) Plasma phospholipid trans fatty acids, fatal ischemic heart disease, and sudden cardiac death in older adults: the cardiovascular health study. Circulation 114 209-215.

4. Chavarro JE, Stampfer MJ, Campos H, Kurth T, Willett WC, et al. (2008) A prospective study of trans-fatty acid levels in blood and risk of prostate cancer. Cancer Epidemiol Biomarkers Prev 17: 95-101.

5. Harris WS, Reid KJ, Sands SA, Spertus JA (2007) Blood omega-3 and trans fatty acids in middle-aged acute coronary syndrome patients. Am $\mathrm{J}$ Cardiol 99: 154-158.

6. Mozaffarian D, Rimm EB, King IB, Lawler RL, McDonald GB, et al. (2004) trans fatty acids and systemic inflammation in heart failure. Am J Clin Nutr 80: 15211525.

7. Sun Q, Ma J, Campos H, Hu FB (2007) Plasma and erythrocyte biomarkers of 
Citation: Benatar JR (2014) There is no Relationship with Plasma Fatty Acid Levels in New Zealanders with Severe Coronary Artery and Mortality. J Nutr Disorders Ther 4: 146. doi:10.4172/2161- 0509.1000146

dairy fat intake and risk of ischemic heart disease. Am J Clin Nutr 86: 929-937.

8. Mozaffarian D, Katan MB, Ascherio A, Stampfer MJ, Willett WC (2006) Trans fatty acids and cardiovascular disease. N Engl J Med 354: 1601-1613.

9. Oomen CM, Ocke MC, Feskens EJ, van Erp-Baart MA, Kok FJ, et al. (2001) Association between trans fatty acid intake and 10-year risk of coronary heart disease in the Zutphen Elderly Study: a prospective population-based study. Lancet 357: 746-751.

10. Willett WC, Stampfer MJ, Manson JE, Colditz GA, Speizer FE, et al. (1993) Intake of trans fatty acids and risk of coronary heart disease among women. Lancet 341: 581-585.

11. Huth PJ (2007) Do ruminant trans fatty acids impact coronary heart disease risk? Lipid Technology 19: 59-62.

12. Jakobsen MU, Overvad K, Dyerberg J, Heitmann BL (2008) Intake of ruminant trans fatty acids and risk of coronary heart disease. Int J Epidemiol 37: 173-182.

13. Booker CS, Mann JI (2008) Trans fatty acids and cardiovascular health: translation of the evidence base. Nutr Metab Cardiovasc Dis 18: 448-456.

14. Laake I, Pedersen JI, Selmer R, Kirkhus B, Lindman AS, et al. (2012) A prospective study of intake of trans-fatty acids from ruminant fat, partially hydrogenated vegetable oils, and marine oils and mortality from CVD. $\mathrm{Br} J$ Nutr 108: 743-754

15. Hooper L, Summerbell CD, Thompson R, Sills D, Roberts FG, et al. (2012) Reduced or modified dietary fat for preventing cardiovascular disease. Cochrane Database Syst Rev 5: CD002137.

16. Hooper L, Summerbell CD, Thompson R, Sills D, Roberts FG, et al. (2011) Reduced or modified dietary fat for preventing cardiovascular disease. Cochrane Database Syst Rev: CD002137.

17. Chowdhury R, Warnakula S, Kunutsor S, Crowe F, Ward HA, et al. (2014) Association of Dietary, Circulating, and Supplement Fatty Acids With Coronary RiskA Systematic Review and Meta-analysis. Annals of Internal Medicine 160: 398-406

18. Siri-Tarino PW, Sun Q, Hu FB, Krauss RM (2010) Meta-analysis of prospective cohort studies evaluating the association of saturated fat with cardiovascular disease. Am J Clin Nutr 91: 535-546.

19. Schaefer EJ, Augustin JL, Schaefer MM, Rasmussen H, Ordovas JM, et al. (2000) Lack of efficacy of a food-frequency questionnaire in assessing dietary macronutrient intakes in subjects consuming diets of known composition. The American Journal of Clinical Nutrition 71: 746-751.

20. Schaefer EJ, Augustin JL, Schaefer MM, Rasmussen H, Ordovas JM, et al. (2000) Lack of efficacy of a food-frequency questionnaire in assessing dietary macronutrient intakes in subjects consuming diets of known composition. Am $\mathrm{J}$ Clin Nutr 71: 746-751.

21. Dougherty RM, Galli C, Ferro-Luzzi A, lacono JM (1987) Lipid and phospholipid fatty acid composition of plasma, red blood cells, and platelets and how they are affected by dietary lipids: a study of normal subjects from Italy, Finland, and the USA. Am J Clin Nutr 45: 443-455.

22. Montfoort A, Baker RWR, Thompson RHS, Zilkha KJ (1966) Plasma phospholipids and their fatty acid composition in multiple sclerosis. Journal of Neurology, Neurosurgery \& Psychiatry 29: 99-102.

23. Karen A. Hicks HMJH, Kenneth W. Mahaffey, Roxana Mehran, Steven E. Nissen, Norman L. Stockbridge, Shari L. Targum, Robert Temple;on behalf of the Standardized Data Collection for Cardiovascular Trials Initiative (2012) Standardized Definitions for Cardiovascular and Stroke End Point Events in Clinical Trials.

24. Authority NZFS (2009) 2009 New Zealand Total Diet Study:Simulated Die Review.

25. Dobson W.D. (1997) The evolution of New Zealand's dairy board :implications for the board's single desk (monopoly) exporting privilege. The Babcock Institute for International Dairy Research and Development, University of Wisconsin.

26. Daley C, Abbott A, Doyle P, Nader G, Larson S (2010) A review of fatty acid profiles and antioxidant content in grass-fed and grain-fed beef. Nutrition
Journal 9: 10.

27. Benatar JR, Gladding P, White HD, Zeng I, Stewart RA (2011) Trans-fatty acids in New Zealand patients with coronary artery disease. Eur J Cardiovasc Prev Rehabil 18: 615-620.

28. Tholstrup T, Raff M, Basu S, Nonboe P, Sejrsen K, et al. (2006) Effects of butter high in ruminant trans and monounsaturated fatty acids on lipoproteins, incorporation of fatty acids into lipid classes, plasma C-reactive protein, oxidative stress, hemostatic variables, and insulin in healthy young men. Am J Clin Nutr 83: 237-243.

29. Motard-Belanger A, Charest A, Grenier G, Paquin P, Chouinard Y, et al. (2008) Study of the effect of trans fatty acids from ruminants on blood lipids and other risk factors for cardiovascular disease. Am J Clin Nutr 87: 593-599.

30. Hu FB, Stampfer MJ, Manson JE, Ascherio A, Colditz GA, et al. (1999) Dietary saturated fats and their food sources in relation to the risk of coronary heart disease in women. Am J Clin Nutr 70: 1001-1008.

31. Wakai K, Naito M, Date C, Iso H, Tamakoshi A, et al. (2014) Dietary intakes of fat and total mortality among Japanese populations with a low fat intake: the Japan Collaborative Cohort (JACC) Study. Nutrition \& Metabolism 11: 12.

32. Estruch R, Ros E, Salas-Salvado J, Covas MI, Pharm D, et al. (2013) Primary Prevention of Cardiovascular Disease with a Mediterranean Diet. N Engl J Med 14: $1279-1290$

33. Mozaffarian D, Micha R, Wallace S (2010) Effects on coronary heart disease of increasing polyunsaturated fat in place of saturated fat: a systematic review and meta-analysis of randomized controlled trials. PLoS Med 7: e1000252.

34. DiNicolantonio JJ (2014) The cardiometabolic consequences of replacing saturated fats with carbohydrates or $\Omega-6$ polyunsaturated fats: Do the dietary guidelines have it wrong? Open Heart 1

35. Gross LS, Li L, Ford ES, Liu S (2004) Increased consumption of refined carbohydrates and the epidemic of type 2 diabetes in the United States: an ecologic assessment. The American Journal of Clinical Nutrition 79: 774-779.

36. Zakeri R, Freemantle N, Barnett V, Lipkin GW, Bonser RS, et al. (2005) Relation Between Mild Renal Dysfunction and Outcomes After Coronary Artery Bypass Grafting. Circulation 112: I-270-I-275.

37. Hannan EL, Wu C, Bennett EV, Carlson RE, Culliford AT, et al. (2006) Risk Stratification of In-Hospital Mortality for Coronary Artery Bypass Graft Surgery. Journal of the American College of Cardiology 47: 661-668.

38. Newby P, Muller D, Hallfrisch J, Andres R, Tucker KL (2004) Food patterns measured by factor analysis and anthropometric changes in adults. The American Journal of Clinical Nutrition 80: 504-513. 